\title{
Inhaled 5-methoxy- $N, N$-dimethyltryptamine: Supportive context associated with positive acute and enduring effects
}

\author{
NATHAN D. SEPEDA ${ }^{1}$, JOHN M. CLIFTON ${ }^{1}$, LAURA Y. DOYLE ${ }^{1}$, RAFAEL LANCELOTTA $^{2}$, ROLAND R. GRIFFITHS ${ }^{1,3}$ and \\ ALAN K. DAVIS ${ }^{1,4} *$ \\ ${ }^{1}$ Center for Psychedelic and Consciousness Research, Department of Psychiatry and Behavioral Sciences, Johns Hopkins School of \\ Medicine, Baltimore, MD, USA \\ ${ }^{2}$ School of Counseling, Leadership, Advocacy, and Design, University of Wyoming, Laramie, WY, USA \\ ${ }^{3}$ Department of Neuroscience, Johns Hopkins School of Medicine, Baltimore, MD, USA \\ ${ }^{4}$ College of Social Work, The Ohio State University, Columbus, OH, USA
}

(Received: September 16, 2019; accepted: November 28, 2019)

\begin{abstract}
Background and aims: 5-Methoxy- $N, N$-dimethyltryptamine (5-MeO-DMT) is a potent, short-acting psychedelic that produces strong hallucinogenic effects. The association between the context (i.e., set and setting) of 5-MeO-DMT use and the acute and enduring effects of the substance is unknown. Therefore, this study examined these associations using secondary data from two cross-sectional survey studies. Methods: The acute and enduring effects of inhaled synthetic 5-MeO-DMT were compared between individuals who used 5-MeO-DMT in a non-structured context (NSC; $n=216$, female $=10 \%, M_{\mathrm{age}}=35.5, S D=11.8$ ) and those who used in a structured context (SC; $n=362$, female $\left.=45 \%, M_{\mathrm{age}}=47.7, S D=13.3\right)$. Questionnaires were administered online and responses were anonymized for privacy purposes. Respondents were asked to retrospectively rate their first experience with synthesized 5-MeO-DMT on measures of mystical experience, challenging experience, and enduring effects. Results: Both groups endorsed high ratings on the Mystical Experience Questionnaire; however, mean scores were significantly higher in the SC group compared to the NSC group. Similarly, the proportion of respondents who had a complete mystical experience was significantly larger in the SC group (83\%) compared to the NSC group (54\%). Ratings of enduring effects (i.e., meaningfulness, spirituality, and well-being) were also significantly higher, and the intensity of challenging experiences was significantly lower, in the SC group compared to the NSC group. Conclusions: 5-MeO-DMT appears to occasion mystical-type experiences with enduring positive effects, which are more intense when 5-MeO-DMT is administered in a safe and supportive context. Future prospective experimental studies should examine the effects of 5-MeO-DMT and its interactive relationship with supportive contextual factors.
\end{abstract}

Keywords: 5-MeO-DMT, psychedelics, context, set and setting, mystical experience, challenging experience

\section{INTRODUCTION}

5-Methoxy- $N, N$-dimethyltryptamine (5-MeO-DMT) is a psychoactive indolealkylamine found in plants (e.g., virola resin, anadenanthera peregrina seeds, and Dictyoloma incanescens; Ott, 2001), in the venom of Bufo alvarius toads (Lyttle, Goldstein, \& Gartz, 1996; Weil \& Davis, 1994), and can be produced synthetically (Hoshino \& Shimodaira, 1936). 5-MeO-DMT has been described as producing strong hallucinogenic effects (e.g., auditory/visual distortions, changes in time perception, and emotional experiences) with a rapid onset and a short duration of action (Davis, Barsuglia, Lancelotta, Grant, \& Renn, 2018; Ott, 2001; Shulgin \& Shulgin, 1997), and has been administered via several routes, including intranasal, sublingual, oral, buccal, intravenous, intramuscular, and inhalation (Davis et al., 2018; Ott, 2001). When inhaled, which is the most common route of administration (Davis et al., 2018), the peak effects of 5-MeO-DMT occur within seconds and last up to $20 \mathrm{~min}$ (Ott, 2001). Furthermore, 5-MeO-DMT has been used in a variety of settings, including recreational environments (e.g., someone's home, concert, and nature) and structured groups (e.g., psychospiritual/ritualistic contexts; Davis, So, Lancelotta, Barsuglia, \& Griffiths, 2019).

Similar to other classic psychedelic substances [e.g., psilocybin, lysergic acid diethylmide (LSD), and dimethyltryptamine (DMT)], 5-MeO-DMT acts as an agonist at $5-\mathrm{HT}_{1 \mathrm{~A}}$ and $5-\mathrm{HT}_{2 \mathrm{~A}}$ receptors and is a full agonist for 5- $\mathrm{HT}_{1 \mathrm{~A}}$ receptors (Dumuis, Sebben, \& Bockaert, 1988; Jiang, Shen, \& Yu, 2016; Nichols, 2016; Spencer, Glaser, \& Traber, 1987). In addition to similar receptor activity, 5-MeO-DMT is similar to some classic psychedelics in molecular structure (Ott, 2001; Ray, 2010), intensity of subjective ratings of mystical or spiritual effects

* Corresponding author: Alan K. Davis, PhD; College of Social Work, The Ohio State University, 1947 College Rd, Columbus, OH 43210, USA; Phone: +1 704219 1733; E-mail: davis.5996@ osu.edu

This is an open-access article distributed under the terms of the Creative Commons Attribution-NonCommercial 4.0 International License, which permits unrestricted use, distribution, and reproduction in any medium for non-commercial purposes, provided the original author and source are credited, a link to the CC License is provided, and changes - if any - are indicated. 
(Barsuglia et al., 2018), behavioral effects (Halberstadt et al., 2011; Krebs-Thomson, Ruiz, Masten, Buell, \& Geyer, 2006; Nichols, 2016), and neuronal effects (Carhart-Harris et al., 2012; Riga, Soria, Tudela, Artigas, \& Celada, 2014).

Because emerging evidence suggests similarities between the acute effects of 5-MeO-DMT and other classic psychedelic substances, studies have explored whether 5-MeO-DMT is associated with positive outcomes on mental health and well-being. For example, akin to evidence that psilocybin improves various mental health symptoms when administered under supportive contexts (Carhart-Harris et al., 2016; Garcia-Romeu, Griffiths, \& Johnson, 2014; Griffiths et al., 2016; Grob et al., 2011; Ross et al., 2016), recent evidence suggests that 5-MeO-DMT use, reported in cross-sectional surveys and observational prospective studies, is related to self-reported improvement of a variety of mental health symptoms including anxiety, depression, substance use problems, and posttraumatic stress disorder (Cox, Lancelotta, Barsuglia, \& Davis, 2018; Cox, Moshman, Barsuglia, Lancelotta, \& Davis, 2018; Davis et al., 2019; Uthaug et al., 2019).

Positive clinical outcomes after ingesting psychedelics (e.g., psilocybin and 5-MeO-DMT) have been associated with certain phenomenological features of the experience (e.g., mystical-type experiences; Davis et al., 2019; GarciaRomeu et al., 2014; Griffiths et al., 2016; Ross et al., 2016). Specifically, mystical-type experiences are characterized as profound experiences of deeply felt positive mood, a feeling of oneness or unity with the surrounding world, a sense of sacredness or reverence, a sense of intuition or experience of profound truths about reality, transcendence of time and space, and difficulty describing the experience in words (Barrett, Johnson, \& Griffiths, 2015; Griffiths, Richards, McCann, \& Jesse, 2006; Pahnke \& Richards, 1966; Stace, 1960). Recent research has shown that classic psychedelics, including 5-MeO-DMT, may occasion mystical-type experiences (Davis et al., 2018; Griffiths et al., 2006; Griffiths, Hurwitz, Davis, Johnson, \& Jesse, 2019), and the occurrence of mystical-type experiences is predictive of positive changes in attitudes, mood, behavior, and spirituality (Davis et al., 2019; Garcia-Romeu et al., 2014; Griffiths, Richards, Johnson, McCann, \& Jesse, 2008, Griffiths et al., 2016, 2018; Ross et al., 2016). It is important to note, however, that the content of psychedelic experiences can often vary, and the occurrence of mystical-type experiences may not be necessary for the attribution of beneficial outcomes (Carbonaro et al., 2016; Carbonaro, Johnson, Hurwitz, \& Griffiths, 2018).

Although psychedelic use has been associated with positive effects, challenging or difficult experiences sometimes occur (Barrett, Bradstreet, Leoutsakos, Johnson, \& Griffiths, 2016; Carbonaro et al., 2016; Davis et al., 2018). Challenging experiences are described as acute physical and psychological experiences that can include feelings of fear, anxiety, paranoia, sadness, loss of sanity, depressed mood, dissociation, and physical distress (Barrett et al., 2016). Although these feelings can be acutely challenging, they may sometimes also be associated with positive enduring effects (Carbonaro et al., 2016). A recent study by Davis et al. (2018) found that 5-MeO-DMT users reported a variety of challenging experiences (e.g., felt heart beating, fear, frightened, and body shake/tremble). Overall, however, these challenging experiences were rated as "very slight." Most current research studies involving administration of psychedelics utilize procedures to mitigate these challenging experiences and facilitate the positive effects of psychedelics by optimizing the context (i.e., set and setting; Leary, Litwin, \& Metzner, 1963) of the psychedelic experience. Such procedures include providing safe and supportive settings, carefully screening study participants, preparing study participants for a psychedelic experience, and developing a trusting relationship between the participant and study staff (Johnson, Richards, \& Griffiths, 2008). Furthermore, a recent study of individuals who reported a challenging experience after taking psilocybin indicates that social support, trust for others present, physical comfort, and safety within the environment can alleviate challenging experiences (Carbonaro et al., 2016).

Although a structured and supportive context is assumed to enhance the positive effects and reduce the challenging effects of any psychedelic, including 5-MeO-DMT, no empirical investigation has tested this hypothesis among people who use 5-MeO-DMT. Therefore, this study sought to examine the associations between context and the acute subjective and enduring effects of 5-MeO-DMT by comparing survey responses of two subsamples of individuals. The first subsample is composed of individuals from the general population who reported using 5-MeO-DMT in a variety of non-structured contexts (NSC; e.g., their home/ apartment, a friend's house/apartment, a festival; Davis et al., 2018). The second group is composed of individuals who reported using 5-MeO-DMT in a specific structured context (SC) in the Western United States (Davis et al., 2019), with procedures for dosing and administration of 5-MeO-DMT, and preparing for and supporting participants during and following drug administration. Because evidence suggests that procedures aimed at providing a safe and supportive environment for psychedelic experiences are associated with an increase in mystical-type experiences and a decrease in challenging experiences (Carbonaro et al., 2016; Lancelotta \& Davis, 2019), we hypothesized that those in the SC subsample would report significantly more intense mystical experiences, more enduring positive effects, and less intense challenging experiences compared to those in NSC subsample.

\section{METHODS}

\section{Respondents and procedure}

This study is a secondary analysis of two published survey studies (Davis et al., 2018, 2019). One sample was composed of people who used 5-MeO-DMT in an NSC (Davis et al., 2018), and the other contains people who used 5-MeO-DMT as part of a SC in the Western US (Davis et al., 2019). For this study, respondents from the NSC subsample were recruited using written Internet advertisements, banner ads on several web pages (including Facebook), and through snowball methods via e-mail communication. Respondents from the SC subsample were recruited via an e-mail distribution list of people belonging 
to a specific group that administers 5-MeO-DMT to members in a supportive setting (see description below). The survey was identical for both subsamples. Once at the secure survey study site, all respondents viewed an informed consent document and were notified that $\$ 2 /$ respondent (up to \$250) would be donated to the Multidisciplinary Association for Psychedelic Studies for their participation (the organization was not otherwise involved in the study). To be eligible for the study, respondents must have been able to read and understand English, have used 5-MeO-DMT at least once in their lifetime, and be at least 18 years old. As revealed in earlier reports from these data sets (Davis et al., 2018, 2019), there were no respondents in the current sample who were classified as careless responders or had duplicate IP addresses. No personally identifying information was collected as part of the study.

Respondents were recruited from April to August 2017. In effort to control for differences in route of administration and the type of 5-MeO-DMT used, only respondents who reported inhaling synthesized 5-MeO-DMT were included in this study. The entire sample of individuals in the SC study ( $n=362$; Davis et al., 2019) was included because they all inhaled (i.e., smoked/vaporized) synthesized 5-MeO-DMT, and individuals in the NSC study $(n=515$; Davis et al., 2018) were excluded if they reported consuming other sources of 5-MeO-DMT (e.g., plant-based, toad bufotoxin; $n=231$ ) or if they reported consuming synthesized 5-MeO-DMT via routes of administration other than smoked or vaporized (e.g., swallowed and snorted; $n=68$ ). The final sample $(n=578)$ for this study was composed of 362 individuals from the SC study and 216 from the NSC study.

\section{The SC subsample}

Description of the procedures that guided the administration of 5-MeO-DMT in the SC subsample has been reported previously (Davis et al., 2019). Briefly, established in 2007, this organization was started with the intention to create a safe environment for the ceremonial use of 5-MeO-DMT. The organization uses synthesized 5-MeO-DMT, which is tested in a laboratory (gas chromatography mass spectrometry; range $=98 \%-100 \%$ pure). New members must be at least 21 years old, referred and sponsored by a current member, undergo a health screening, and participate in an orientation session that provides information about the effects of 5-MeO-DMT. Members must also be willing to help maintain the physical and mental safety of the session environment. Sessions, which are conducted in a variety of locations in the Western US, include 5-12 people (1-2 facilitators who administer 5-MeO-DMT) and last approximately 6-7 hr.

Each session in the SC begins with the intention of cocreating a calm space, providing physical comfort of the attendees, and listening to prerecorded music. This is followed by a brief "check-in" with each attendee (e.g., giving name, current feeling, and an intention for the session). Next, an attendee is administered a dose of 5-MeO-DMT by means of inhalation (via custom crafted, argon gas, and piston vaporizer), whereas the other attendees attend to the person receiving the dose and assist the facilitators in providing a safe space for the individual. The experience lasts approximately $35-45 \mathrm{~min}$. This procedure is repeated with the next attendee, until everyone has received 5-MeO-DMT. The conclusion of the session includes a brief "check-out" during which each attendee shares their thoughts about the experience. Attendees are also encouraged to spend time "integrating" their experiences with others by attending a future gathering with group members, and by writing about their experience or thinking about it while in nature.

\section{The NSC subsample}

The setting of the respondents from the NSC subsample could include a variety of geographic locations and various environments in which one had used 5-MeO-DMT. Data from the current subsample indicated that all of the NSC respondents inhaled (i.e., smoked/vaporized) their 5-MeO-DMT. NSC respondents reported using 5-MeODMT alone $(36 \%)$ or with one other person present $(32 \%)$, and usually at their own or at their friends' apartment or house $(75 \%)$. In addition, over three quarters $(80 \%)$ of respondents in this sample reported administering 5-MeODMT themselves, and only a small proportion (37\%) reported integrating their experience with others. Most NSC respondents reported that they obtained the substance from the Internet $(37 \%)$ or from a friend (37\%), with limited information about the dose and purity of the substance.

\section{Measures}

\section{Questions assessing patterns of 5-MeO-DMT use}

The survey included questionnaires examining patterns of use of 5-MeO-DMT. Respondents were asked to retrospectively rate their frequency of 5-MeO-DMT use (More than once per month, About once each month, Less than once per month but more than once per year, About once per year, and Less than once per year) and their number of lifetime doses (1-20, 21, or more).

\section{Acute mystical experience}

The Mystical Experience Questionnaire (MEQ) was used to examine the acute mystical effects that could occur after taking a hallucinogen (Barrett et al., 2015; Griffiths et al., 2006; MacLean, Leoutsakos, Johnson, \& Griffiths, 2012). Respondents were asked to think back on the first experience they had with 5-MeO-DMT and rate the intensity with which they had each of 30 effects at any point during that session on a 6-point scale ranging from $0=$ "None; not at all" to 5= "Extreme." The MEQ has four subscales: (a) Mystical, (b) Positive mood, (c) Transcendence of time/ space, and (d) Ineffability. The mean of the total MEQ score was used to assess the overall intensity of mystical experience. Moreover, similar to a previous study (Barrett et al., 2015), the proportion of respondents who experienced a "complete mystical experience" was calculated (i.e., those whose mean score for each of the four MEQ subscales was 
at least $60 \%$ of the total possible score). Internal consistency of each scale was excellent (Cronbach's $\alpha$ range $=.92-.98$ ).

\section{Acute challenging experiences}

The Challenging Experiences Questionnaire (CEQ) was used to examine the physically and psychologically difficult experiences that could occur after taking a hallucinogen (Barrett et al., 2016). Respondents were asked to think back on the first experience they had with 5-MeO-DMT and rate the intensity with which they had each of 26 effects at any point during that session on a 6-point scale from $0=$ "None; not at all" to 5= "Extreme." The CEQ is composed of seven subscales: (a) Fear, (b) Grief, (c) Physical Distress, (d) Insanity, (e) Isolation, (f) Death, and (g) Paranoia. The mean of the total CEQ score was used to examine the overall intensity of challenging effects. Internal consistency of each scale in the current sample was good to excellent (Cronbach's $\alpha$ range $=.62-.93$ ).

\section{Beliefs about the enduring effects of 5-MeO-DMT}

Three items from the Persisting Effects Questionnaire (Griffiths et al., 2006, 2008, 2011) were used, in which respondents rated the extent to which their first 5-MeODMT experience was spiritually significant (on a scale from $0=$ "Not at all" to $5=$ "The single most spiritually significant experience of my life") and personally meaningful (on a scale from $0=$ "No more than routine, everyday experiences" to $7=$ "The single most meaningful experience of my life"). Item 3 assessed the degree to which each respondent believed their first 5-MeO-DMT experience had contributed to changes in their sense of personal well-being or life satisfaction (on a scale from $-3=$ "Decreased very much" to 3 = "Increased very much"). The overall mean for each item was calculated and was used in each analysis.

\section{Demographics and substance use questionnaires}

Respondents were asked to report several demographic characteristics, including age, gender (male/female), ethnicity (White/non-White), sexual orientation (heterosexual/ non-heterosexual), country of residence [United States (US)/non-US country], employment status (part time, full time, and unemployed), and level of education (high school or less, trade or some college/Associate's degree/Bachelor's degree/Master's degree).

\section{Data analyses}

Demographic characteristics, 5-MeO-DMT patterns of use characteristics, intensity of acute mystical and challenging effects, and beliefs about the enduring effects of 5-MeO-DMT were all examined in the overall sample. The sample was then split into two based on whether a respondent was classified as from the SC study (Davis et al., 2019) or from the NSC study (Davis et al., 2018), and a series of $\chi^{2}$ analyses and $t$-tests were used to compare study variables between the two subsamples. An $\alpha$ of .05 was used to determine whether to reject the null hypothesis in each analysis and effect sizes (Cohen's $d$ and $\phi$ ) were calculated for each test to assist with interpreting the strength of effects. Analyses were conducted using SPSS v.24 (IBM Corp, 2016).

\section{Ethics}

The study was deemed exempt by the human subjects review board of Bowling Green State University. All research participants were presented with an informed consent document and gave notice of their consent by clicking "Next" and completing the online survey.

\section{RESULTS}

\section{Respondents' characteristics}

Table 1 shows that the majority of respondents resided in the USA (73\%) and were Caucasian (86\%), heterosexual (80\%), and male $(68 \%)$ with a mean age of 43.1 years $(S D=14.1)$. The SC subsample was significantly older $\left(M_{\text {age }}=47.7\right.$, $S D=13.3$ vs. $\left.M_{\text {age }}=35.5, S D=11.8\right)$, composed of more females ( $45 \%$ vs. $10 \%)$, mostly from the US (100\% vs. $47 \%$ ), and had higher levels of educational attainment, such as a Bachelor's (39\% vs. $25 \%$ ) or Master's (36\% vs. $19 \%$ ) degree, compared to those from the NSC subsample (see Table 1 for further demographic characteristics).

\section{Differences in lifetime and frequency of 5-MeO-DMT use}

There was a significant difference in lifetime use of $5-\mathrm{MeO}-\mathrm{DMT}$ between subsamples, $\chi^{2}(3, N=577)=$ $41.43, p<.001$. Post-hoc tests of between-group comparisons revealed that a significantly larger proportion of respondents in the SC subsample (51\%) reported using 5-MeO-DMT "1-2 times" in their lifetime compared to only $32 \%$ of respondents in the NSC subsample. Moreover, a smaller proportion of respondents in the SC subsample $(10 \%)$ reported using 5-MeO-DMT " $11+$ " times in their lifetime compared to respondents in the NSC subsample (29\%). Respondents in both subsamples reported infrequent use of 5-MeO-DMT, with the majority of those in the SC subsample (64\%) and the NSC subsample (62\%), indicating they had used 5-MeO-DMT less than once per year. However, there was a significant difference in overall frequency of 5-MeO-DMT use between the two subsamples, $\chi^{2}(3, N=421)=21.51, p<.001$. Specifically, the post-hoc comparisons revealed that the proportion of respondents reporting 5-MeO-DMT use "Once per month or more" was significantly smaller among those in the SC subsample (4\%) compared to those in the NSC subsample $(15 \%)$. Furthermore, the proportion of respondents indicating they use 5-MeO-DMT "About once per year" also differed significantly between those in the SC subsample $(33 \%)$ and those in the NSC subsample (23\%).

\section{Comparison of acute mystical and challenging experiences}

As Figure 1 shows (statistical tests reported in Table 2), compared to those in the NSC subsample respondents in the 
Table 1. Demographic characteristics among individuals within the total sample and differences in characteristics between those in the structured context and non-structured context subsamples

\begin{tabular}{|c|c|c|c|c|c|}
\hline $\begin{array}{l}\text { Demographic } \\
\text { characteristics }\end{array}$ & $\begin{array}{l}\text { Total sample } \% \\
\quad(n=578)\end{array}$ & $\begin{array}{l}\text { Non-structured context } \\
\text { subsample } \%(n=216)\end{array}$ & $\begin{array}{c}\text { Structured context } \\
\text { subsample \% }(n=362)\end{array}$ & $\chi^{2}$ statistic & $\begin{array}{c}\text { Effect } \\
\text { size }(\phi)^{\mathrm{a}}\end{array}$ \\
\hline Gender & & & & $73.842 * * *$ & 0.36 \\
\hline Female & 32.3 & 10.1 & 45.4 & & \\
\hline Male & 67.7 & 89.9 & 54.6 & & \\
\hline Ethnicity & & & & 1.055 & 0.04 \\
\hline White & 85.5 & 87.4 & 84.4 & & \\
\hline Non-White & 14.5 & 12.6 & 15.6 & & \\
\hline Sexual orientation & & & & 0.561 & 0.03 \\
\hline Heterosexual & 79.6 & 81.2 & 78.6 & & \\
\hline Non-heterosexual & 20.4 & 18.8 & 21.4 & & \\
\hline Employment & & & & 0.624 & 0.03 \\
\hline Part time or full time & 65.1 & 67.1 & 63.9 & & \\
\hline Unemployed & 34.9 & 32.9 & 36.1 & & \\
\hline Educational attainment & & & & $64.78 * * *$ & 0.34 \\
\hline High school or less & 9.7 & 18.5 & 4.4 & & \\
\hline Trade or some college & 22.0 & 31.9 & 16.1 & & \\
\hline Associate's degree & 5.4 & 6.0 & 5.0 & & \\
\hline Bachelor's degree & 33.4 & 25.0 & 38.5 & & \\
\hline Master's degree & 29.5 & 18.5 & 36.0 & & \\
\hline Country & & & & $121.864 * * *$ & 0.36 \\
\hline United States (US) & 72.9 & 46.5 & 100.0 & & \\
\hline Non-US country & 27.1 & 53.5 & 0.0 & & \\
\hline
\end{tabular}

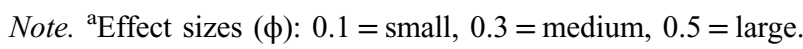

$* * * p<.001$.

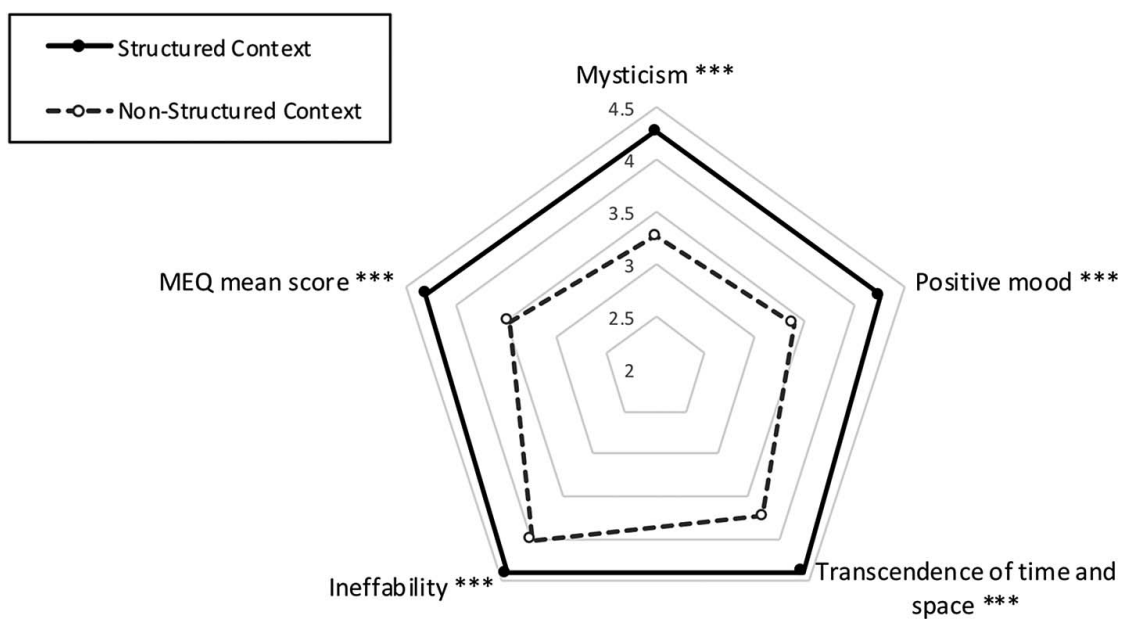

Figure 1. Visual depiction of differences in mean scores on the Mystical Experience Questionnaire (MEQ) between the structured context and non-structured context subsamples. 6-point scale from $0=$ "None; not at all" to $5=$ "Extreme." *** $p<.001$

SC subsample reported significantly higher scores on all four subscales, as well as the overall mean score, of the MEQ. Furthermore, there was a significant difference in the proportion of each subsample that met criteria for a "complete mystical experience" (83\% in the SC subsample vs. $54 \%$ in the NSC subsample), $\chi^{2}(1, N=578)=58.08, p<.001$. As shown in Figure 2 (statistical tests reported in Table 2), the overall mean CEQ scores reported by respondents in the NSC subsample were significantly higher than those reported by respondents in the SC subsample. Moreover, respondents in the SC subsample reported significantly lower scores on six of the seven subscales of the CEQ. Notably, the mean intensity of challenging experiences in both subsamples was low, with a score of 1 indicating "very slight" on a scale from $0=$ "None; not at all" to $5=$ "Extreme".

\section{Comparison of enduring effects of 5-MeO-DMT use}

An assessment of enduring effects related to the 5-MeODMT experience revealed that respondents in the SC subsample $(M=4.00, S D=0.94)$ attributed significantly higher levels of spiritual significance to their 5-MeO-DMT experience compared to respondents in the NSC subsample $(M=2.91, S D=1.59), t=9.14, p<.001, d=0.79$. Furthermore, respondents in the SC subsample $(M=5.79$, $S D=1.04$ ) attributed significantly higher ratings of personal 
Table 2. Comparison of means (and standard deviations) of scores on the Mystical Experience and Challenging Experience Questionnaires between respondents in the structured context and non-structured context subsamples

\begin{tabular}{|c|c|c|c|c|}
\hline & $\begin{array}{l}\text { Non-structured context } \\
\text { subsample }(n=216)\end{array}$ & $\begin{array}{l}\text { Structured context } \\
\text { subsample }(n=362)\end{array}$ & $\begin{array}{c}\text { Difference between groups } \\
\text { ( } t \text {-statistic) }\end{array}$ & $\begin{array}{l}\text { Effect size } \\
(\text { Cohen's } d)^{\mathrm{a}}\end{array}$ \\
\hline \multicolumn{5}{|c|}{ Mystical Experience Questionnaire (MEQ) } \\
\hline Mysticism & $3.26(1.42)$ & $4.26(0.98)$ & $9.114 * * *$ & 0.79 \\
\hline Positive mood & $3.38(1.32)$ & $4.25(1.07)$ & $8.257 * * *$ & 0.71 \\
\hline $\begin{array}{l}\text { Transcendence of } \\
\text { time and space }\end{array}$ & $3.74(1.37)$ & $4.39(0.94)$ & $6.217 * * *$ & 0.54 \\
\hline Ineffability & $4.01(1.30)$ & $4.41(0.97)$ & $3.868^{* * *}$ & 0.33 \\
\hline Total score & $3.46(1.23)$ & $4.30(0.89)$ & $8.816^{* * *}$ & 0.76 \\
\hline \multicolumn{5}{|c|}{ Challenging Experience Questionnaire (CEQ) } \\
\hline Isolation & $0.85(1.25)$ & $0.41(0.91)$ & $4.585 * * *$ & 0.40 \\
\hline Fear & $1.39(1.43)$ & $0.96(1.28)$ & $3.626 * * *$ & 0.31 \\
\hline Grief & $0.68(1.01)$ & $0.89(1.07)$ & $2.458^{*}$ & 0.21 \\
\hline Physical distress & $1.21(1.13)$ & $0.91(0.89)$ & $3.352 * * *$ & 0.29 \\
\hline Insanity & $0.95(1.31)$ & $0.53(1.01)$ & $4.003 * * *$ & 0.35 \\
\hline Death & $1.77(1.91)$ & $1.46(1.73)$ & 1.941 & 0.17 \\
\hline Paranoia & $0.16(0.55)$ & $0.04(0.31)$ & $2.825 * * *$ & 0.24 \\
\hline Total score & $1.01(0.95)$ & $0.79(0.77)$ & $2.929 * * *$ & 0.25 \\
\hline
\end{tabular}

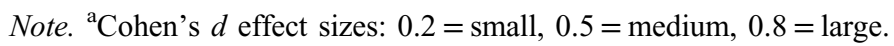

${ }^{*} p<.05 . * * * p .001$.

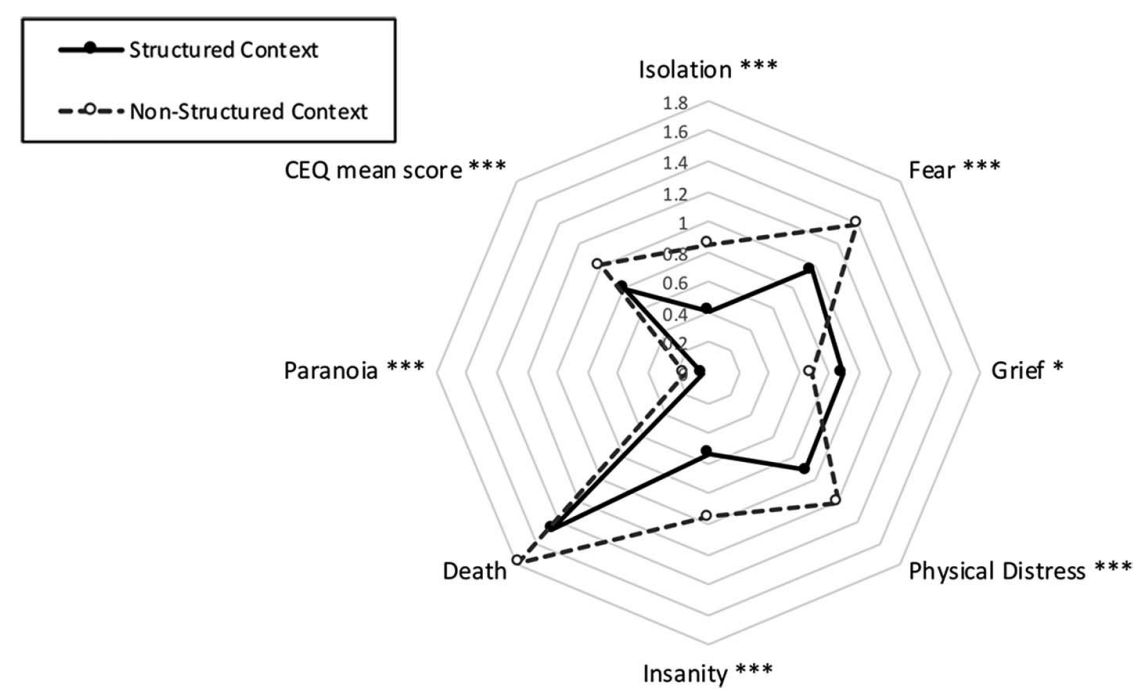

Figure 2. Visual depiction of differences in mean scores on the Challenging Experience Questionnaire (CEQ) between the structured context and non-structured context subsamples. 6-point scale from $0=$ "None; not at all" to $5=$ "Extreme." $* p<.05$. ${ }^{* * *} p<.001$

meaning to their 5-MeO-DMT experience compared to the respondents in the NSC subsample $(M=4.63, S D=1.86)$, $t=8.43, p<.001, d=0.73$. Finally, respondents in the SC subsample $(M=2.34, S D=0.99)$ reported that their 5-MeO-DMT experience led to significantly more positive changes in their sense of personal well-being and life satisfaction compared to respondents in the NSC subsample $(M=1.55, S D=1.17), t=8.30, p<.001, d=0.72$.

\section{DISCUSSION}

This study sought to determine whether the retrospective report of acute and enduring effects of 5-MeO-DMT differed between individuals using 5-MeO-DMT in a SC and those using it in an NSC. Findings of this study suggest that 5-MeO-DMT administration may occasion mystical-type experiences and that such effects occur at significantly higher intensity when administered in a context that provides a supportive structure, guides the dosing and administration of 5-MeO-DMT, and encourages the preparation for and support during and after drug administration. Furthermore, individuals who used 5-MeO-DMT in a SC reported lower scores of challenging experience and attributed higher levels of personal meaning, spiritual significance, and improved subjective well-being to their 5-MeODMT experience compared to respondents from the NSC.

The respondents from the SC subsample had their 5-MeO-DMT session with an experienced guide/facilitator who spent time helping prepare participants for their 
session, administered 5-MeO-DMT via a standardized procedure, provided music during the session, and encouraged participants to integrate the experience immediately after, and in the days/weeks following, the session. These practices are consistent with Johnson et al. (2008) and practices used in recent laboratory studies (Carbonaro et al., 2018; Garcia-Romeu et al., 2014; Griffiths et al., 2006, 2008, $2011,2016)$. For example, facilitators in laboratory studies are involved in ensuring whether participants are prepared for their psychedelic experience, spending time developing rapport, providing safety and psychosocial support, and then integrating the experience into the person's life after the psychedelic experience (Johnson et al., 2008). The overlap in the procedures used to conduct psychedelic sessions in the laboratory and the procedures of the SC subsample could explain the differences of higher positive and lower negative ratings between the SC and NSC groups, and may provide a possible explanation of prior findings from the SC subsample (Davis et al., 2019), in which most participants had experienced positive changes in depression and anxiety following 5-MeO-DMT use. In addition, those in the SC were more likely to be female, reside in the USA, and report higher levels of education than the NSC group, which may or may not be related to their report of acute and enduring experiences with 5-MeO-DMT. Moreover, because other factors may also contribute to retrospective reports of psychedelic experiences (e.g., dose, expectations, and memory), findings from this study should be replicated using laboratory or longitudinal procedures to test the causal effects of such procedures.

This study has several limitations. First, the study utilized a retrospective self-report survey introducing the possibility for recall and selection biases. Respondents who had positive experiences with 5-MeO-DMT may have been more likely to participate. Although the drug and dose administered were standardized for those respondents in the SC subsample, the drug and dose used by those in the NSC subsample were unknown. It is also possible that the substance used in the NSC subsample may not have been 5-MeO-DMT. In addition, expectancy was not assessed in this study, thereby making it impossible to know in what ways expectancy contributed to the outcomes observed. It is also possible that characteristic differences between the SC and NSC subsamples (e.g., age, gender, educational attainment, and country of origin) may have contributed to differences in the reports of acute and enduring effects. However, there are no previous reports that suggest these characteristics differentially influence scores on the MEQ or CEQ, possibly tempering this limitation. This study did not directly assess aspects of "set" (i.e., mood or mindset) or other possible contributing factors (e.g., absorption, prior drug knowledge, and personality), and therefore cannot determine whether these factors contributed to the outcomes observed. Moreover, the survey used in this study did not assess whether respondents from either subsample were screened for psychiatric and medical conditions by medical professionals, nor did it assess whether respondents were evaluated for current medication use and potential contraindications. Future research should address these limitations by assessing participant mood and personality, and experimentally manipulating context in a prospective double-blind study in which 5-MeO-DMT is administered to carefully screened participants.

The findings of this study highlight the importance of the context in which 5-MeO-DMT is administered. When administered under supportive conditions, 5-MeO-DMT use appears to be associated with meaningful experiences marked by higher intensity of mystical-type experiences and lower levels of challenging experiences. These findings extend prior literature by examining the effect of context on the acute effects of 5-MeO-DMT used in naturalistic settings and demonstrate that contextual factors should be considered as elements that support the physical and psychological wellbeing of those who choose to ingest 5-MeO-DMT. Because of the public health importance of reducing harm associated with substance use (Marlatt, Larimer, \& Witkiewitz, 2011), and the mounting concern about physical and emotional harm experienced during 5-MeO-DMT sessions (Thoricatha, 2018), clinicians and harm reduction workers could use these findings to ensure that people who seek out experiences with 5-MeO-DMT are knowledgeable about the potential benefits associated with using 5-MeO-DMT in a supportive context to help people make evidenced-based decisions about their substance use.

Acknowledgements: During his work on this study, AKD was supported by a NIDA T32 training grant (no. DA007209). RL was financially supported by Source Research Foundation for administrative and research assistance on this project. RRG was supported by a NIDA grant (R01DA003889). Support for the Center for Psychedelic and Consciousness Research was provided by the Steven and Alexandra Cohen foundation and from Tim Ferriss, Matt Mullenweg, Craig Nerenberg, and Blake Mycoskie.

Conflict of interest: RRG is a member of the Board of Directors of the Heffter Research Institute. AKD and RL are members of the Board of Directors of the Source Research Foundation. The other authors declared no potential conflicts of interest with respect to the research, authorship, and/ or publication of this article.

\section{REFERENCES}

Barrett, F., Bradstreet, M., Leoutsakos, J., Johnson, M., \& Griffiths, R. (2016). The Challenging Experience Questionnaire: Characterization of challenging experiences with psilocybin mushrooms. Journal of Psychopharmacology, 30(12), 1279-1295. doi:10.1177/0269881116678781

Barrett, F., Johnson, M., \& Griffiths, R. (2015). Validation of the revised Mystical Experience Questionnaire in experimental sessions with psilocybin. Journal of Psychopharmacology, 29(11), 1182-1190. doi:10.1177/0269881115609019

Barsuglia, J., Davis, A., Palmer, R., Lancelotta, R., WindhamHerman, A., Peterson, K., Polanco, M., Grant, R., \& Griffiths, R. (2018). Intensity of mystical experiences occasioned by 5-MeO-DMT and comparison with a prior psilocybin study. Frontiers, 9, 1-6. doi:10.3389/fpsyg.2018.02459 
Carbonaro, T., Bradstreet, M., Barrett, F., MacLean, K., Jesse, R., Johnson, M., \& Griffiths, R. (2016). Survey study of challenging experiences after ingesting psilocybin mushrooms: Acute and enduring positive and negative consequences. Journal of Psychopharmacology, 30(12), 1268-1278. doi:10.1177/ 0269881116662634

Carbonaro, T., Johnson, M., Hurwitz, E., \& Griffiths, R. (2018). Double-blind comparison of the two hallucinogens psilocybin and dextromethorphan: Similarities and differences in subjective experiences. Psychopharmacology, 235(2), 521-534. doi:10.1007/s00213-017-4769-4

Carhart-Harris, R. L., Bolstridge, M., Rucker, J., Day, C. M., Erritzoe, D., Kaelen, M., Bloomfield, M., Rickard, J. A., Forbes, B., Feilding, A., Taylor, D., Pilling, S., Curran, V. H., \& Nutt, D. (2016). Psilocybin with psychological support for treatment-resistant depression: An open-label feasibility study. Lancet Psychiatry, 3(7), 619-627. doi:10.1016/ S2215-0366(16)30065-7

Carhart-Harris, R. L., Erritzoe, D., Williams, T., Stone, J., Reed, L., Colasantia, A., Tyacke, R. J., Leech, R., Malizia, A. L., Murphy, K., Hobden, P., Evans, J., Feilding, A., Wise, R. G., \& Nutt, D. (2012). Neural correlates of the psychedelic state as determined by fMRI studies with psilocybin. Proceedings of the National Academy of Sciences of the United States of America, 109(6), 2138-2143. doi:10.1073/pnas.1119598109

Cox, K. E., Lancelotta, R., Barsuglia, J. P., \& Davis, A. K. (2018). 5-MeO-DMT and subjective improvements in post traumatic stress disorder. Poster session presented at the Annual Convention of the Maryland Psychological Association, Baltimore, MD. Retrieved from https://www.researchgate.net/publication/ 328676027_5-MeO-DMT_and_subjective_improvements_in_ post-traumatic_stress_disorder

Cox, K. E., Moshman, S. A., Barsuglia, J. P., Lancelotta, R., \& Davis, A. K. (2018). Subjective improvements in substance use problems following 5-MeO-DMT use in an international sample. Poster session presented at the Annual Poster Symposium of the Behavioral Pharmacology Research Unit, Baltimore, MD. Retrieved from https://www.researchgate. net/publication/326468791_Subjective_improvements_in_ substance_use_problems_following_5-MeO-DMT_use_in_ an_international_sample

Davis, A., Barsuglia, J., Lancelotta, R., Grant, R., \& Renn, E. (2018). The epidemiology of 5-methoxy- $N, N$-dimenthyltryptamine (5-MeO-DMT) use: Benefits, consequences, patterns of use, subjective effects, and reasons for consumption. Journal of Psychopharmacology, 32(7), 779-779. doi:10.1177/0269881 118769063

Davis, A., So, S., Lancelotta, R., Barsuglia, J., \& Griffiths, R. (2019). 5-Methoxy- $N, N$-dimethyltryptamine (5-MeO-DMT) used in a naturalistic setting is associated with unintended improvements in depression and anxiety. The American Journal of Drug and Alcohol Abuse, 45(2), 161-169. doi:10.1080/ 00952990.2018.1545024

Dumuis, A., Sebben, M., \& Bockaert, J. (1988). Pharmacology of 5-hydroxytryptamine-1A receptors which inhibit cAMP production in hippocampal and cortical neurons in primary culture. Molecular Pharmacology, 33(2), 178-186. Retrieved from http://molpharm.aspetjournals.org/content/33/2/178

Garcia-Romeu, A., Griffiths, R., \& Johnson, M. (2014). Psilocybinoccasioned mystical experiences in the treatment of tobacco addiction. Current Drug Abuse Reviews, 7(3), 157-164. doi:10. 2174/1874473708666150107121331

Griffiths, R., Johnson, M., Carducci, M., Umbricht, A., Richards, W., Richards, B., Cosimano, M. P., \& Klinedinst, M. (2016). Psilocybin produces substantial and sustained decreases in depression and anxiety in patients with life-threatening cancer: A randomized double-blind trial. Journal of Psychopharmacology, 30(12), 1181-1197. doi:10.1177/02698811166 75513

Griffiths, R. R., Johnson, M. W., Richards, W. A., Richards, B. D., Jesse, R., MacLean, K. A., Barrett, F. S., Cosimano, M. P., \& Klinedinst, M. A. (2018). Psilocybin-occasioned mystical-type experience in combination with meditation and other spiritual practices produces enduring positive changes in psychological functioning and in trait measures of prosocial attitudes and behavior. Journal of Psychopharmacology, 32(1), 49-69. doi:10.1177/0269881117731279

Griffiths, R., Johnson, M., Richards, W. A., Richards, B. D., McCann, U., \& Jesse, R. (2011). Psilocybin occasioned mystical-type experiences: Immediate and persisting dose related effects. Psychopharmacology, 218(4), 649-665. doi:10.1007/s00213-011-2358-5

Griffiths, R., Richards, W., Johnson, M., McCann, U., \& Jesse, R. (2008). Mystical-type experiences occasioned by psilocybin mediate the attribution of personal meaning and spiritual significance 14 months later. Journal of Psychopharmacology, 22(6), 621-632. doi:10.1177/0269881108094300

Griffiths, R., Richards, W., McCann, U., \& Jesse, R. (2006). Psilocybin can occasion mystical-type experiences having substantial and sustained personal meaning and spiritual significance. Psychopharmacology, 187(3), 268-283. doi:10. 1007/s00213-006-0457-5

Griffiths, R. R., Hurwitz, E. S., Davis, A. K., Johnson, M. W., \& Jesse, R. (2019). Survey of subjective "God encounter experiences": Comparisons among naturally occurring experiences and those occasioned by the classic psychedelics psilocybin, LSD, ayahuasca, or DMT. PLoS One, 14(4), e0214377. doi:10.1371/journal.pone.0214377

Grob, C., Danforth, A., Chopra, G., Hagerty, M., McKay, C., Halberstadt, A., \& Greer, G. (2011). Pilot study of psilocybin treatment for anxiety in patients with advanced-stage cancer. Archives of General Psychiatry, 68(1), 71-78. doi:10.1001/ archgenpsychiatry.2010.116

Halberstadt, A., Koedood, L., Powell, S., \& Geyer, M. (2011). Differential contributions of serotonin receptors to the behavioral effects of indoleamine hallucinogens in mice. Journal of Psychopharmacology, 25(11), 1548-1561. doi:10.1177/ 0269881110388326

Hoshino, T., \& Shimodaira, K. (1936). Über die synthese des bufotenin-methyl- äthers (5-methoxy-n-dimethyl-tryptamin) und bufotenins (synthesen in der indol-gruppe. xv). Bulletin of the Chemical Society of Japan, 11(3), 221-224. doi:10.1246/bcsj.11.221

IBM Corp. (2016). IBM SPSS Statistics for Windows, Version 24.0. Armonk, NY: IBM Corp.

Jiang, X., Shen, H., \& Yu, A. (2016). Modification of 5-methoxy- $N$, $\mathrm{N}$-dimethyltryptamine-induced hyperactivity by monoamine oxidase A inhibitor harmaline in mice and the underlying serotonergic mechanisms. Pharmacological Reports, 68(3), 608-615. doi:10.1016/j.pharep.2016.01.008 
Johnson, M., Richards, W., \& Griffiths, R. (2008). Human hallucinogen research: Guidelines for safety. Journal of Psychopharmacology, 22(6), 603-620. doi:10.1177/0269881108093587

Krebs-Thomson, K., Ruiz, E., Masten, V., Buell, M., \& Geyer, M. (2006). The roles of 5- $\mathrm{HT}_{1 \mathrm{~A}}$ and $5-\mathrm{HT}_{2}$ receptors in the effects of 5-MeO-DMT on locomotor activity and prepulse inhibition in rats. Psychopharmacology, 189(3), 319-329. doi:10.1007/ s00213-006-0566-1

Lancelotta, R., \& Davis, A. K. (2019). Use of benefit enhancement strategies among 5-methoxy- $N$, $N$-dimethyltryptamine (5-MeODMT) users: Associations with mystical, challenging, and enduring effects. Journal of Psychoactive Drugs.

Leary, T., Litwin, G., \& Metzner, R. (1963). Reactions to psilocybin administered in a supportive environment. The Journal of Nervous and Mental Disease, 137(6), 561-573. doi:10.1097/ 00005053-196312000-00007

Lyttle, T., Goldstein, D., \& Gartz, J. (1996). Bufo toads and bufotenine: Fact and fiction surrounding an alleged psychedelic. Journal of Psychoactive Drugs, 28(3), 267-290. doi:10.1080/02791072.1996.10472488

MacLean, K., Leoutsakos, J., Johnson, M., \& Griffiths, R. (2012). Factor analysis of the Mystical Experience Questionnaire: A study of experiences occasioned by the hallucinogen psilocybin. Journal for the Scientific Study of Religion, 51(4), 721-737. doi:10.1111/j.1468-5906.2012.01685.x

Marlatt, G. A., Larimer, M. E., \& Witkiewitz, K. (Eds.). (2011). Harm reduction: Pragmatic strategies for managing high-risk behaviors (2nd ed.). New York, NY: The Guilford Press.

Nichols, D. (2016). Psychedelics. Pharmacological Reviews, 68(2), 264-355. doi:10.1124/pr.115.011478

Ott, J. (2001). Pharmepéna-psychonautics: Human intranasal, sublingual, and oral pharmacology of 5-methoxy- $N$, $\mathrm{N}$-dimethyltryptamine. Journal of Psychoactive Drugs, 33(4), 403-407. doi:10.1080/02791072.2001.10399925

Pahnke, W. N., \& Richards, W. A. (1966). Implications of LSD and experimental mysticism. Journal of Religion and Health, 5(3), 175-208. doi:10.1007/BF01532646

Ray, T. (2010). Psychedelics and the human receptorome. PLoS One, 5(2), e9019. doi:10.1371/journal.pone.0009019
Riga, M., Soria, G., Tudela, R., Artigas, F., \& Celada, P. (2014). The natural hallucinogen 5-MeO-DMT, component of ayahuasca, disrupts cortical function in rats: Reversal by antipsychotic drugs. The International Journal of Neuropsychopharmacology, 17(8), 1269-1282. doi:10.1017/S1461145714000261

Ross, S., Bossis, A., Guss, J., Agin-Liebes, G., Malone, T., Cohen, B., Mennenga, S. E., Belser, A., Kalliontzi, K., Babb, J., Su, Z., Corby, P., \& Schmidt, B. (2016). Rapid and sustained symptom reduction following psilocybin treatment for anxiety and depression in patients with life-threatening cancer: A randomized controlled trial. Journal of Psychopharmacology, 30(12), 1165-1180. doi:10.1177/026988111 6675512

Shulgin, A., \& Shulgin, A. (1997). TiHKAL: The continuation. Berkeley, UK: Transform Press.

Spencer, D. G., Glaser, T., \& Traber, J. (1987). Serotonin receptor subtype mediation of the interoceptive discriminative stimuli induced by 5 -methoxy- $N, N$-dimethyltryptamine. Psychopharmacology (Berlin), 93(2), 158-166. doi:10.1007/BF001 79927

Stace, W. T. (1960). Mysticism and philosophy. New York, NY: MacMillan Press.

Thoricatha, W. (2018). Underground 5-MeO-DMT facilitators: The Good, The Bad, and The Ugly with James Oroc. Psychedelic Times. Retrieved from https://psychedelictimes.com/ underground-5-meo-dmt-facilitators-james-oroc/

Uthaug, M. V., Lancelotta, R., van Oorsouw, K., Kuypers, K. P. C., Mason, N., Rak, J., Šuláková, A., Jurok, R., Maryška, M., Kuchař, M., Páleníček, T., Riba, J., \& Ramaekers, J. G. (2019). A single inhalation of vapor from dried toad secretion containing 5-methoxy- $N, \quad N$-dimethyltryptamine (5-MeODMT) in a naturalistic setting is related to sustained enhancement of satisfaction with life, mindfulness-related capacities, and decrement of psychopathological symptoms. Psychopharmacology, 236(9), 2653-2666. doi:10.1007/s00213-01905236-w

Weil, A. T., \& Davis, W. (1994). Bufo alvarius: A potent hallucinogen of animal origin. Journal of Ethnopharmacology, 41(1-2), 1-8. doi:10.1016/0378-8741(94)90051-5 